\title{
Scientific Explanation of Phenomenon, Imagination and Concept Formation as Correlates of Students' Understanding of Physics Concepts
}

\author{
B. C. Madu, PhD \\ Department of Science Education, University of Nigeria, Nsukka \\ Ogundeji, Oluwatomisin Marvellous \\ Federal University, Gusau, Zamfara State \\ Nestor Ekemezie Okoye \\ Federal College of Education (Technical), Umunze
}

\begin{abstract}
Knowledge of physics to many students is described in quantitative terms such as how much scientific vocabulary and how many formulae have been memorized. However, only few students can successfully make connections to apply the scientific knowledge in answering questions in physics. That is, physics students answer questions in relation to their emergent views mainly based on their prior knowledge about everyday experience which is at variance with scientific knowledge in a typical physics classroom. It is evident that teaching and learning of physics concepts introduced in verbal and mathematical definitions may not promote conceptual understanding of physics even after instruction. Therefore, no relationship exists between students, prior knowledge in physics and scientific understanding of physics concepts as they attempt to answer physics questions that probe their scientific understanding. Hence, the main purpose of this study was to ascertain if relationship exist among scientific explanation of phenomenon, imagination and concept formation (predictor variables) and students' understanding of physics concepts (criterion) and amount of variation in the criterion variable that can be attributed to the predictor variables. The study adopted a correlation research design. The sample of the study was 385 respondents drawn from the population of Senior Secondary III Physics Students of 2016/2017 academic session in the government owned secondary schools in Akure Education Zone of Ondo State. The instruments for data collection were four namely: Students' Scientific Explanation of Phenomenon Test (SSEPT), Students' Scientific Imagination Scale (SSIS), Students' Scientific Concept Formation Test (SSCFT), and Students' Understanding of Physics Concept Test (SUPCT). SSEPT and SUPCT were ten (10) structured essay questions each. The internal consistency indices obtained were 0.81 and 0.86 respectively. An internal consistency of twenty (20) item structured questionnaire of (SSIS), modeled on a four (4) point rating was determined using Cronbach Alpha formula and was found to be scale 0.85 .Also, the internal consistence index of SSCFT with twenty multiple choice items was determined using Kuder-Richardson 20 (K-R20) Formula and was found to be 0.82. The research questions were answered using Pearson-Product Moment Correlation and coefficient of determination The Null hypotheses were tested using Multiple-Regression analysis at.05 level of significance. Results showed that there was a statistically significant relationship among students' scientific explanation of phenomenon, students' scientific imagination, students' scientific concept formation and students' understanding of physics concepts. It was recommended among other things that Physics teachers should help in fostering conceptual understanding of physics concepts in physics students using scientific explanation of phenomenon to trigger students' scientific imagination and students' scientific concept formation.
\end{abstract}

Keywords: Scientific Phenomenon, Scientific Imagination, Concept Formation, Understanding, Physics.

DOI: $10.7176 / \mathrm{JNSR} / 11-16-03$

Publication date: August $31^{\text {st }} 2020$

\section{Introduction}

Science and Technology are two basic concepts which cannot be separated from one another. Science and technology in the view of Ezenwa and Gambari (2011) are important components of the knowledge to be given to citizens irrespective of tribe/ethnicity, creed or gender. Jegede and Awodun (2013) claimed that science and technology is incomplete without proper understanding of basic principles of physics. Physics is one of the science subjects taught at the Senior Secondary School Level of Nigeria educational system. Hence, the training of science students to acquire proper understanding of basic principles of physics as well as its applications becomes the aim of physics teaching and learning in the secondary schools.

Lack of proper understanding of concepts goes a long way to confuse students in the physics classroom. Physics students, therefore, experience conceptual blockages in the construction of knowledge and may remain unaware of other blockages of physics concepts ( $\mathrm{Ng}$ and Nguyen, 2006). To the extent that when they are strongly 
attached to their false conception, students may be unwilling to accept the scientific view of the concept offered by their teachers. For instance, it is assumed that students will not develop a scientific understanding of DC circuits, if they do not accept scientific reasoning about electric current (Madu, 2009). Electric current is the key concept that students use to explain the phenomenon in a circuit whereas voltage is poorly understood concept and it is usually identified with current.

Also, the idea that physics teaching and learning is problem solving, may not promote understanding of concepts. Students' reasoning is, therefore, based solely on mathematical definition, without an understanding of the way physical quantities are related (Gunstone in Kim \& Pak, 2001). Common difficulties in understanding basic concepts of physics are observed when students respond to questions that are into probing, conceptual understanding (Gunstone in Kim \& Pak, 2001). Recent research in physics education shows that many students still retain fundamental conceptual difficulties even after instruction (Ugwanyi, 2012; \& Orji, 2013). Thus, students' understanding of physics concepts is limited and this leads to low correlation between conceptual understanding and the number of solved problems (Kim \& Pak, 2001).

Although, many researchers have used several approaches and developed several models towards bringing students to understanding physics concepts. Examples of such include: the use of problem solving, conceptual change pedagogy (CCP), and cognitive conflict instructional (CCI) approach (Madu, 2003; Orji, 2013). But, in the opinion of Adeyemo (2010), Physics concepts which could be acquired through abstraction requires a higher level of conceptualization based on meaningful experience for better understanding to take place. To raise the level of understanding of physics concepts therefore, illustrations by models must be taken beyond their physical limitations. This involves the ability to apply concepts learnt in everyday phenomena that students observe and experience around them.

In achieving this, Ostergaard, Dahlin, and Hugo (2007) have developed stepwise approach of bridging phenomena and new scientific concepts. This shows a relationship between explanation of phenomenon and understanding of physics concepts. The role of phenomenological studies to enhance students' understanding was also revealed in Viennot (2003) and McDermott (2006). Griffith and Brosing (2009) affirm that many of the basic concepts of physics become clearer if applied to everyday phenomena. This agrees with the deductive view of science toward the use of explanation in science for clarification of concepts, justification of beliefs or actions and theoretical derivations of laws, thus, making science relevant in students' learning.

Meanwhile, explanations given by students on scientific phenomenon corresponds to their level of imagination (Oluwatelure, 2002). Hence, in the context of science, imagination is a highly regarded human value which systematically questions the understanding of the world. Imaginations are by nature introverted private activity (meaning subjective nature of human being) yet it is the duty of physics teacher to aid students in their scientific imagination and concept formation for scientific/conceptual understanding.

Skinner (2003) therefore, advocated for the role of imagination in physics so as to teach an authentic physics to future physicists as well as scientific literacy to the general public. According to Egan (1992) students as well as teachers should be imaginatively engaged in teaching and learning process; and learning how to engage students' imaginations should have a central place in teacher-preparation programme. The implication is that students' understanding of physics concepts could be attained when emphasis is placed on 'imaginative learning' and its relevance in teaching and learning of physics. That is, students could view objects, events, and phenomenon with an objective mind in learning truth usually documented in textbooks. This is in line with educational implication of Piaget's theory on cognitive development which emphasized that at formal operational stage (12 - 16 years) children are capable of abstract reasoning and could sometimes demonstrate this through logical use of symbols relating to abstract concepts. Thus, Students are said to be capable of reasoning hypothetically and deductively.

In the cognitive science, how concepts are formed in student's mind and most importantly how they are connected with each other was termed deep understanding (Grotzer, 1999). The term deep understanding was used by Grotzer (1999), and Ostergaard et al., (2007) to mean scientific understanding. Girard and Wong (2002) stated that deep understanding requires both knowledge of and the ability to use scientific concepts to develop mental models about the way the world operates in accordance with a current scientific theory. According to Colman (2003) Concepts are related to phenomenon of conceiving ideas or thoughts about concrete or abstract matters. They are means of producing knowledge and organizing ideas to categorize information. Knowledge is a product of learning. Nnachi (2009) refers to processes of concept learning to mean as concept formation.

Concept formation entails discernment of properties common to class of object which may involve discrimination training (Chance, 1994). Kaur (2014) views this training as a classification activity, using item characteristics for classification. This classification activity is what Kaur refers to as concept formation. Parker (2008) opined that concept formation is an inductive teaching strategy that helps students to form a clear understanding of a concept (or idea) through studying a small set of examples of the concept. It is therefore pertinent to say that concept formation process which involves categorization and classification activity may lead students to understanding of physics concepts.

According to $\mathrm{Ng}$ and Nguyen (2006), the use of phenomenon in physics teaching at high schools was reported 
to improve students' understanding of physics concepts. Michelini. Santi, Stefanel and Vercellati (2014) shows a relationship between exploring magnetic phenomena to develop formal thinking/reasoning while, Amsel and Johnston (2008) shows relationship between students' imagination and conceptual change. Khan (2011) studied the existing level of understanding of chemistry concepts among class IX students by administering achievement test to investigate the effectiveness of concept formation teaching model over traditional method on class IX students. The study shows positive relationship as it promotes students understanding of chemistry concepts.

From the foregoing, it is therefore evident that students' understanding of physics concepts may not be attained under teaching and learning approaches that favors rote incorrect prior knowledge. But, looking from scientific enterprises perspective, teaching and learning approach that will bridge the gap between everyday experience and science-based knowledge is expected to actively engage students in their own construction of understanding. In Vietnamse high schools, the use of everyday phenomena in physics teaching and learning is currently in use. In Nigeria, as observed in developing countries, making physics education becoming more relevant in students' learning by involving the ability to draw in examples from everyday phenomenon and applying concepts learnt into familiar everyday phenomena is expected to aid students' understanding of physics concepts. The current study seeks to find out how scientific explanation of phenomenon, imagination and concept formation correlates with students' understanding of physics concepts.

\section{Purpose of the Study}

The purpose of the study is to ascertain if relationship exists among scientific explanation of phenomenon, imagination and concept formation to students' understanding of physics concepts. Specifically, the study seeks to ascertain the relationship

- between scientific explanation of phenomenon and students' understanding of physics concepts and amount of variation in students' understanding of physics concepts attributed to scientific explanation of phenomenon

- between scientific imagination and students' understanding of physics concepts and amount of variation in students' understanding of physics concepts attributed to scientific imagination.

- between scientific concept formation and students' understanding of physics concepts and amount of variation in students' understanding of physics concepts attributed to scientific concept formation

- among scientific explanation of phenomenon, scientific imagination and students' understanding of physics concepts and amount of variation in students' understanding of physics concepts attributed to scientific explanation of phenomenon and scientific imagination

- among scientific imagination, scientific concept formation and students' understanding of physics concepts and amount of variation in students' understanding of physics concepts attributed to scientific imagination and concept formation

- $\quad$ among scientific explanation of phenomenon, scientific concept formation and students' understanding of physics concepts and amount of variation in students' understanding of physics concepts attributed to scientific explanation of phenomenon and concept formation.

- $\quad$ among scientific explanation of phenomenon, scientific imagination, scientific concept formation and students' understanding of physics concepts and amount of variation in students' understanding of physics concepts attributed to scientific explanation of phenomenon, scientific imagination and concept formation

\section{Research Questions}

The following research questions were formulated to guide the study:

- What is the relationship between students' scientific explanation of phenomenon and students' understanding of physics concepts and amount of variation in students' understanding of physics concepts attributed to scientific explanation of phenomenon?

- What is the relationship between students' scientific imagination and students' understanding of physics concepts and amount of variation in students' understanding of physics concepts attributed to scientific imagination?

- What is the relationship between students' scientific concept formation and students' understanding of physics concepts and amount of variation in students' understanding of physics concepts attributed to scientific concept formation?

- What is the relationship among students' scientific explanation of phenomenon, students' scientific imagination and students' understanding of physics concepts and amount of variation in students' understanding of physics concepts attributed to scientific explanation of phenomenon and scientific imagination?

- What is the relationship among students' scientific imagination, students' scientific concept formation 
and students' understanding of physics concepts and amount of variation in students' understanding of physics concepts attributed to scientific imagination and concept formation?

- What is the relationship among students' scientific explanation of phenomenon, students' scientific concept formation and students' understanding of physics concepts and amount of variation in students' understanding of physics concepts attributed to scientific explanation of phenomenon and concept formation?

- What is the relationship among students' scientific explanation of phenomenon, students' scientific imagination, students' scientific concept formation and students' understanding of physics concepts and amount of variation in students' understanding of physics concepts attributed to scientific explanation of phenomenon, scientific imagination and concept formation?

\section{Hypotheses}

The following null hypotheses are formulated for the study and will be tested at $\mathrm{p}<$.O5 level of significant:

$\mathrm{Ho}_{1}$ : There is no statistically significant relationship between students' scientific explanation of phenomenon and students' understanding of physics concepts,

$\mathrm{Ho}_{2}$ : There is no statistically significant relationship between students' scientific imagination and students' understanding of physics concepts.

$\mathrm{Ho}_{3}$ : There is no statistically significant relationship between students' scientific concept formation and students' understanding of physics concepts.

Ho4: There is no statistically significant relationship among students' scientific explanation of phenomenon, students' scientific imagination and students' understanding of physics concepts.

Ho5: There is no statistically significant relationship among students' scientific imagination, students' scientific concept formation and students' understanding of physics concepts.

Ho6: There is no statistically significant relationship among students' scientific explanation of phenomenon, students' scientific concept formation and students' understanding of physics concepts.

$\mathrm{Ho}_{7}$ : There is no statistically significant relationship among students' scientific explanation of phenomenon, students' scientific imagination, students' scientific concept formation and students' understanding of physics concepts.

\section{Methodology}

A correlation research design was adopted for this study. According to Nworgu (2015) correlation research study establishes what relationship exists between two or more variables which is used to determine the amount of variation in the students' understanding of physics concepts (criterion variable) attributed to students' scientific explanation of phenomenon, scientific imagination and scientific concept formation (predictor variables). The population of the study comprised of all the SS III physics students for 2015/2016 academic session of all the government owned secondary schools in Akure Education Zone of Ondo State. The choice of 55 III students was because the units to be used for the study are contained in SS I, II, III scheme of work and it was believed that the students were expected to have gained understanding of the concepts under study. Also, it was observed that students' reasoning about physics concepts was based solely on quantitative definition, without an understanding of the way physical quantities are related. The sampled size for this study consisted of 385 Senior Secondary III Physics Students. Proportionate stratified random sampling was used to select thirty schools out of the fifty three schools contained in Akure Education Zone. Three from Akure North, Fifteen from Akure South, Six from Idanre and Six Ifedore Local Government Areas of Akure Education Zone of Ondo State. Proportionate Stratified Random Sampling was used to select 10\% (223) SS III physics students present in selected sampled schools of Akure South L.G.A and 5\% SS III physics students from the sampled schools of Akure North, Idanre and Ifedore (i.e. $41,55,66$ respectively).

Four instruments were used for the study, namely: Students' Scientific Explanation of Phenomenon Test (SSEPT), Students' Scientific Imagination Scale (SSIS), Students' Scientific Concept Formation Test (SSCFT), and Students' Understanding of Physics Concept Test (SUPCT). SSEPT was an open ended questionnaire with ten items. Marking and Scoring of the SSEPT was done by two teachers independently. SSIS had twenty items which was also developed by the researchers and was rated on four point scale (i.e. 4= Strongly Agreed, SA; 3= Agree, A; $2=$ Disagree, D; 1= Strongly Disagree, SD). SSCFT had twenty items which was also developed by the items with four options ranging from A - D. In each item, there is a right key (correct option of the item) that meets the appropriate physics concepts. This means that the instrument was dichotomously scored (i.e. 1 and 0 ). Where 1 mark $=$ correct physics concept and others $0=$ wrong physics concept. The fourth instrument SUPCT had ten essay questions and the Marking and Scoring of SUPCT was done by two teachers independently.

The items were validated by two experts in Measurement \& Evaluation, two in physics education and one expert in physics and astronomy, all in University of Nigeria, Nsukka. Content validation of SSEPT, SSCFT and SUPCT was established using test blue print. In order to establish the construct validity of SSIS, factor analysis 
was used. All the items that were factorially impure and complex were not selected (i.e. those that fall below the minimum factor loading or loaded on more than one factor). And those items that are factorial pure (those items that loaded on one factor alone) were chosen. SSEPT and SUPCT respectively were reliable using kendel tau. The internal consistency indices obtained were 0.81 and 0.86 respectively. The reliability of SSIS was determined using Cronbach alpha formula. The internal consistency index of the instrument was calculated to be 0.85 . The reliability index of SSCFT was determined using Kudder-Richardson 20 (K-R20) Formula. The internal consistency index of the instrument was calculated to be 0.82 .

The researcher visited the sampled schools to administer copies of the instruments to the students through the assistance of the physics teachers in the respective sampled schools. Physics teachers of the sampled schools were intimated on the major purpose of the study. It was administered to the students in an examination conditions. Direct delivery was used in the administration and retrieval of the instrument. This is to minimize wastage. The scores from SSIS, SSEPT, SSCFT and SUPCT were converted to common scale before usage. The research questions were answered using Pearson Product Moment Correlation and the Null hypotheses were tested using Multiple-Regression analysis at 0.05 level of significance. The data was analyzed and summarized in relation to the research questions and the hypotheses that guided this study.

\section{RESULTS}

The data for answering research questions 1,2 and 3 are presented in table 1

Table 1: Correlation Matrix between the Predictors Variables and the Criterion Variable and amount of variations in the criterion variable that are attributed to predictor variables

\begin{tabular}{lcccc}
\hline Variable & SSEP & SSI & SSCF & SUPC \\
\hline SSEP & 1 & & & \\
SS1 & $0.31(0.10)$ & 1 & & \\
SSCF & $0.52(0.27)$ & $0.42(0.18)$ & 1 & 1 \\
SUPC & $0.62(0.38)$ & $0.37(0.14)$ & $0.60(0.36)$ & 1 \\
\hline
\end{tabular}

SSEP, SS1, SSCF, are Predictors and SUPC is a Criterion Variable $\left(\mathrm{R}^{2}\right)=$ Coefficient of Determination. The figures in parenthesis are variations in the criterion variable attributed to predictor variables as determined by coefficient of determination.

Results in Table 1 showed that the correlation between students' scientific explanation of phenomenon (SSEP) and students' understanding of physics concepts (SUPC) was 0.62. This means that, there exist a direct positive relationship between students' scientific explanation of phenomenon and students' understanding of physics concepts. The coefficient of determination $\left(\mathrm{R}^{2}\right)$ associated with 0.62 was 0.38 . This value indicated that $38 \%$ of variation in students' understanding of physics concepts is attributed to scientific explanation of phenomenon. This is an indication that $62 \%$ of the variation in students' understanding of physics concepts was attributed to other factors other than students' scientific explanation of phenomenon.

Table 1 showed that the correlation between students' scientific imagination (SSI) and students' understanding of physics concepts (SUPC) was 0.37. This means that, there exist a direct positive relationship between students' scientific imagination and students' understanding of physics concepts. The coefficient of determination $\left(\mathrm{R}^{2}\right)$ associated with 0.37 was 0.14 . This value indicated that $14 \%$ of variation in students' understanding of physics concepts was attributed to students' scientific imagination. This is an indication that $86 \%$ of the variation in students' understanding of physics concepts is attributed to other factors other than students' scientific imagination.

Table 1 also revealed the correlation coefficient obtained between students' scientific concept formation (SSCF) and students' understanding of physics concepts (SUPC) to be 0.60 . This means that, there exist a direct positive relationship between students' scientific concept formation and students' understanding of physics concepts. The coefficient of determination (predictive value) 0.36 obtained indicated that $36 \%$ of variation in students' understanding of physics concepts is attributed to students' scientific concept formation. This is an indication that $64 \%$ of the variation in students' understanding of physics concepts is attributed to other factors other than students' scientific concept formation.

Data for answering research questions 4, 5, 6 and 7 are presented in table 2

Table 2: Correlation Matrix among the Predictors Variables and the Criterion Variable and amount of variations in the criterion variable that are attributed to predictor variables

\begin{tabular}{llllcc}
\hline Variable & SSEP, SSI & SSI, SSCF & SSEP, SSCF & SSEP, SSI, SSCF & SUPC \\
\hline SUPC & $0.65(0.42)$ & $0.61(0.37)$ & $0.70(0.49)$ & $0.70(0.49)$ & 1 \\
\hline
\end{tabular}

SSEP, SSI, SSCF are Predictors and SUPC is a Criterion Variable $\left(\mathrm{R}^{2}\right)=$ Coefficient of Determination The figures in parenthesis are variations in the criterion variable attributed to predictor variables as determined by coefficient of determination.

The result in Table 2 showed that the correlation coefficient among students' scientific explanation of 
phenomenon (SSEP), students' scientific imagination (SSI) and students' understanding of physics concepts (SUPC) was 0.65 . This means that, there exist a direct positive relationship among students' scientific explanation of phenomenon, students' scientific imagination and students' understanding of physics concepts. The predictive value associated with 0.65 was 0.42 . This predictive value indicated that $42 \%$ of variation in students' understanding of physics concept was attributed to students' scientific explanation of phenomenon and students' scientific imagination. This is an indication that $58 \%$ of the variation in students' understanding of physics concepts was attributed to other factors other than students' scientific explanation of phenomenon and students' scientific imagination.

Table 2 revealed that the correlation coefficient among students' scientific imagination (SSI), students' scientific concept formation (SSCF) and students' understanding of physics concepts (SUPC) was 0.61. This means that, there exist a direct positive relationship among students' scientific imagination, students' scientific concept formation and students' understanding of physics concepts. The coefficient of determination (R2) associated with the correlation coefficients of 0.6 .1 was 0.37 . This predicted value indicated that, $37 \%$ of variation in students' understanding of physics concepts was attributed to students' scientific imagination and students' scientific concept formation. This is an indication that $63 \%$ of the variation in students' understanding of physics concepts is attributed to other factors other than students' scientific imagination and students' scientific concept formation.

Table 2 also revealed the correlation coefficient among students' scientific explanation of phenomenon, students' scientific concept formation (SSCF), and students' understanding of physics concepts (SUPC) to be 0.70 . This means that, there exist a direct positive relationship among students' scientific explanation of phenomenon, students' scientific concept formation and students' understanding of physics concepts. The coefficient of determination $\left(\mathrm{R}^{2}\right)$ associated with the correlation coefficients of 0.70 was 0.49 . This value indicated that, $49 \%$ of variation in students' understanding of physics concepts' was attributed to students' scientific explanation of phenomenon and students' scientific concept formation. Therefore, $51 \%$ of the variation in students' understanding of physics concepts is attributed to other factors other than students' scientific explanation of phenomenon and students' scientific concept formation.

Meanwhile, there exist a direct positive relationship among students' scientific explanation of phenomenon, students' scientific imagination, students' scientific concept formation and students' understanding of physics concepts, as evident on the correlation coefficient index 0.70 shown in Table 2 . The coefficient of determination $\left(\mathrm{R}^{2}\right)$ associated with the correlation coefficients of 0.70 was 0.49 . This predicated index of $49 \%$ simply means that variation in students' understanding of physics concepts was attributed students' scientific explanation of phenomenon, students' scientific imagination, students' scientific concept formation. While, $51 \%$ of the variation in students' understanding of physics concepts can be attributed to other factors other than students' scientific explanation of phenomenon, students' scientific imagination and students' scientific concept formation.

\section{Hypothesis One}

H01: There is no statistically significant relationship between students' scientific explanation of phenomenon and students' understanding of physics concepts.

Table 3: Regression Analysis of Students' Scientific Explanation of Phenomenon and Students' Understanding of Physics Concepts

\begin{tabular}{llllll}
\hline Model & Sum of Square & Df & Mean Square & F & Sig. \\
\hline Regression & 11857.12 & 1 & 11857.12 & 236.48 & 0.00 \\
Residual & 19203.52 & 383 & 50.14 & & \\
Total & 31060.63 & 384 & & & \\
\hline \multicolumn{2}{c}{$\mathrm{p}<0.05$} & & & &
\end{tabular}

In order to test hypothesis 1 , regression analysis was used. The result in Table 3 showed that an F-ratio of 236.48 with associated exact probability value of 0.00 was obtained. This probability value of 0.00 was compared with .05 set as level of significance for testing the hypothesis and it was found to be significant because 0.00 is less than .05. The null hypothesis which stated that; there is no statistically significant relationship between students' scientific explanation of phenomenon and students' understanding of physics concepts was rejected and inference drawn was that, there was a statistically significant relationship between students' scientific explanation of phenomenon and students' understanding of physics concepts. 


\section{Hypothesis Two}

Ho2: There is no statistically significant relationship between students' scientific imagination and students' understanding of physics concepts.

Table 4: Regression Analysis of Students' Scientific Imagination and Students' Understanding of Physics Concepts

\begin{tabular}{llclcc}
\hline Model & Sum of Square & Df & Mean Square & F & Sig. \\
\hline Regression & 4250.31 & 1 & 4250.31 & 60.72 & 0.00 \\
Residual & 26810.32 & 383 & 70.00 & & \\
Total & 31060.63 & 384 & & & \\
\hline \multicolumn{1}{r}{$\quad \mathrm{P}<.05$} & & & &
\end{tabular}

In order to test hypothesis 2, regression analysis was used. The result in Table 4 shows that an F-ratio of 60.72 with associated exact probability value of 0.00 was obtained. This probability value of 0.00 was compared with 0.05 set as level of significance for testing the hypothesis and it was found to be significant because 0.00 is less than 0.05 . The null hypothesis which stated that; there is no statistically significant relationship between students' scientific imagination and students' understanding of physics concepts was rejected and inference drawn was that, there was a statistically significant relationship between students' scientific imagination and students' understanding of physics concepts.

\section{Hypothesis Three}

Ho3: There is no statistically significant relationship between students' scientific concept formation and students' understanding of physics concepts.

Table 5: Regression Analysis of Students' Scientific Concept Formation and Students' Understanding of Physics Concepts

\begin{tabular}{llllll}
\hline Model & Sum of Square & Df & Mean Square & F & Sig. \\
\hline Regression & 11012.17 & 1 & 11012.17 & 210.37 & 0.00 \\
Residual & 20048.46 & 383 & 52.35 & & \\
Total & 31060.63 & 384 & & & \\
\hline \multicolumn{1}{c}{$\quad \mathrm{P}<.05$} & & & &
\end{tabular}

The result in Table 5 showed that an F-ratio of 210.37 with associated exact probability value of 0.00 was obtained. This probability value of 0.00 was compared with 0.05 set as level of significance for testing the hypothesis and it was found to be significant because 0.00 is less than .05 . The null hypothesis which stated that; there is no statistically significant relationship between students' scientific concept formation and students' understanding of physics concepts was rejected and inference drawn was that, there is a significant relationship between students' scientific concept formation and students' understanding of physics concepts.

\section{Hypothesis Four}

Ho4: There is no statistically significant relationship among students' scientific explanation of phenomenon, students' scientific imagination and students' understanding of physics concepts.

Table 6: Regression Analysis of Students' Scientific Explanation of Phenomenon, Students' Scientific Imagination and Students' Understanding of Physics Concept

\begin{tabular}{llclcc}
\hline Model & Sum of Square & Df & Mean Square & F & Sig. \\
\hline Regression & 12938.07 & 2 & 6469.04 & 136.36 & 0.00 \\
Residual & 18122.56 & 382 & 47.44 & & \\
Total & 31060.63 & 384 & & & \\
\hline \multicolumn{1}{c}{$\mathrm{P}<05$} & & & &
\end{tabular}

The result in Table 6 showed that an F-ratio of 136.36 with associated exact probability value of 0.00 was obtained. This probability value of 0.00 was compared with .05 set as level of significance for testing the hypothesis and it was found to be significant because 0.00 is less than .05 . The null hypothesis that stated that; there is no statistically significant relationship among students' scientific explanation of phenomenon, students' scientific imagination and students' understanding of physics concepts was rejected and inference drawn was that, there was a statistically significant relationship among students' scientific explanation of phenomenon, students' scientific imagination and students' understanding of physics concepts. 


\section{Hypothesis Five}

Ho5: There is no statistically significant relationship among students' scientific imagination, students' scientific concept formation and students' understanding of physics concepts.

Table 7: Regression Analysis of Students' Scientific Imagination, Students' Scientific Concept Formation and Students' Understanding of Physics Concepts

\begin{tabular}{llclcc}
\hline Model & Sum of Square & Df & Mean Square & F & Sig. \\
\hline Regression & 11579.37 & 2 & 5789.68 & 113.53 & 0.00 \\
Residual & 19481.27 & 382 & 51.00 & & \\
Total & 31060.63 & 384 & & & \\
\hline \multicolumn{1}{c}{$\quad \mathrm{P}<.05$} & & & &
\end{tabular}

The result in Table 7 showed that an F-ratio of 113.53 with associated exact probability value of 0.00 was obtained. This probability value of 0.00 was compared with 0.05 set as level of significance for testing the hypothesis and it was found to be significant because 0.00 is less than .05 . The null hypothesis which stated that; there is no statistically significant relationship among students' scientific imagination, students' scientific concept formation and students' understanding of physics concepts was rejected and inference drawn was that, there was a statistically significant relationship among students' scientific imagination, students' scientific concept formation and students' understanding of physics concepts.

\section{Hypothesis Six}

Ho6: There is no statistically significant relationship among students' scientific explanation of phenomenon, students' scientific concept formation and students' understanding of physics concepts.

Table 8: Regression Analysis of Students' Scientific Explanation of Phenomenon, Students' Scientific Concept Formation and Students' Understanding of Physics Concepts

\begin{tabular}{llclll}
\hline Model & Sum of Square & Df & Mean Square & F & Sig. \\
\hline Regression & 15107.721 & 2 & 7553.86 & 180.88 & 0.00 \\
Residual & 15952.913 & 382 & 41.76 & & \\
Total & 31060.63 & 384 & & & \\
\hline \multicolumn{1}{c}{$\mathrm{P}<.05$} & & & &
\end{tabular}

The result in Table 8 showed that an F-ratio of 180.88 with associated exact probability value of 0.00 was obtained. This probability value of 0.00 was compared with .05 set as level of significance for testing the hypothesis and it was found to be significant because 0.00 is less than .05 . The null hypothesis that stated that; there is no statistically significant relationship among students' scientific explanation of phenomenon, students' scientific concept formation and students' understanding of physics concepts was rejected and inference drawn was that, there was a statistically significant relationship among students' scientific explanation of phenomenon, students' scientific concept formation and students' understanding of physics concepts.

\section{Hypothesis Seven}

Ho7: There is no statistically significant relationship among students' scientific explanation of phenomenon, students' scientific imagination, students' scientific concept formation and students' understanding of physics concepts.

Table 9: Regression Analysis of Students' Scientific Explanation of Phenomenon, Students' Scientific Imagination, Students' Scientific Concept Formation and Students' Understanding of Physics Concepts.

\begin{tabular}{llclll}
\hline Model & Sum of Square & Df & Mean Square & F & Sig. \\
\hline Regression & 15359.82 & 3 & 5119.94 & 124.24 & 0.00 \\
Residual & 15700.81 & 381 & 41.21 & & \\
Total & 31060.63 & 384 & & & \\
\hline \multicolumn{2}{c}{$\mathrm{P}<.05$} & & & &
\end{tabular}

The result in Table 9 showed that an F-ratio of 124.24 with associated exact probability value of 0.00 was obtained. This probability value of 0.00 was compared with. 05 set as level of significance for testing the hypothesis and it was found to be significant because 0.00 is less than .05. The null hypothesis which stated that; there is no statistically significant relationship among students' scientific explanation of phenomenon, students' scientific imagination, students' scientific concept formation and students' understanding of physics concepts was rejected and inference drawn was that, students' scientific explanation of phenomenon, students' scientific imagination, students' scientific concept formation is a correlates of students' understanding of physics concepts. In other words, there is a statistically significant relationship among students' scientific explanation of phenomenon, students' scientific imagination, students' scientific concept formation and students' understanding of physics concepts.

\section{Discussion of the Results}

The data obtained indicated that there exist a direct positive relationship between students' scientific explanation 
of phenomenon and students' understanding of physics concepts. The $38 \%$ of the variation in students' understanding of physics concepts was attributed to scientific explanation of phenomenon. This positive relationship leads to significant relationship between students' scientific explanation of phenomenon and students' understanding of physics concepts. The study of $\mathrm{Ng}$ and Nguyen (2006) corroborated this current study on the use of everyday phenomena to deepen students' scientific understanding of physics concepts. Review shows the extent to which teachers provided examples of everyday life phenomena most or all of the time in the teaching of physics in school. Although, Wilkinson (1999) investigation on the use of real life contexts to aid students' conceptual understanding was not very clear from the perception of the Victorian high school teachers, but finding from this study made it clear that scientific explanation of phenomenon facilitates students' understanding of physics concept. This implies that, when a physics concept like electrostatic is to be introduced, the scientific explanation of phenomenon that explains why the cracks or sparks of nylon under garment in the dry weather could be used to deepen the understanding of the physics concepts. Such explanation could be that dry weather is strongly electrified as it comes into contact with nylon under the garments to produce cracks or sparks. The explanation could be that hair on a body is charged, and they exact strong attraction on the nylon materials in a dry weather. Hence, the physics concept electrostatic is best understood as static electricity.

There is positive relationship between students' scientific imagination and students' understanding of physics concepts. $14 \%$ of variation in students' understanding of physics concepts was attributed to students' scientific imagination. This is an indication that the variation in students' understanding of physics concepts may be attributed to other factors which accounted for $86 \%$ other than students' scientific imagination. However, there was a statistically significant relationship between students' scientific imagination and students' understanding of physics concepts. This finding is in agreement with the finding of Amsel and Johnston (2008) which revealed that in both sets of data, students demonstrate more sophisticated understandings when they undertake the scientific view of their teacher. Hence, features of students thinking correlate with the imagining of their teachers perspective. This is an evidence that scientific imagination communicated by the physics teacher aids students' scientific imagination and also promotion of students' understanding of physics concepts was in agreement with findings of this study. However, engaging students' imagination is not simply a matter of techniques, physics teachers must, therefore, be imaginatively engaged. Hence, learning how to engage students' imaginations should have a central place in teachers' preparation of lessons, so as to make it have a reasonable role in the students understanding of physics concepts.

Similarly, there was direct positive relationship between students' scientific concept formation and students' understanding of physics concepts. The $36 \%$ of variation in students' understanding of physics concepts was attributed to students' scientific concept formation and this indicates that $64 \%$ of variation in students' understanding of physics concepts was due to other factors other than students' scientific concept formation. This finding agreed with Yao (2003) findings, who confirm that concept formation would improve students' understanding of concepts since concepts are the basic units of thought that underlie human intelligence and communication at both philosophical level and technique level. Also, the study by Khan (2011) on existing leve1 of understanding of concepts in the science subject among class IX students, with regard to the effectiveness of concept formation teaching model over traditional method on class IX students' achievement showed the supremacy of concept formation teaching model on traditional method. Hence, the ultimate results of the study indicated that concept formation teaching model was more effective as compared to traditional method, since concept formation would improve students' understanding of science concepts. The implication is that scientific physics concepts cannot be understood until the terms by which they are defined have been grasped by the students. Therefore, the formation of physics concepts in the cognitive structure is not purely a result of direct observation and past experience, but by cognitive processes such as organization, interpretation and combination of thoughts.

Further analysis revealed that there was a direct positive relationship among students' scientific explanation of phenomenon, students' scientific imagination and students' understanding of physics concepts. These variables put together account for $42 \%$ of variation in students' understanding of physics concepts, showing that $58 \%$ of the variation in students' understanding of physics concepts was due to other factors other than students' scientific explanation of phenomenon and students' scientific imagination. This is an indication that, students' scientific explanation of phenomenon and students' scientific imagination jointly correlated fairly with the students' understanding of physics concepts. This finding corroborates the findings of Michelini, Santi, Stefanel, and Vercellati, (2014) who revealed that students focus their attention on the relevant physics elements in phenomena and bridge the space between a structural and a functional description of the apparatus. The relationship between the study and this current one is that both emphasized that the phenomena studied would improve students' understanding of physics concepts when taking through formal thinking/reasoning. This implies that scientific phenomenon is experienced through sensation by individual perception and the consciousness that makes the interpretation possible.

There existed a direct positive relationship among students' scientific imagination, students' scientific concept formation and students' understanding of physics concepts. This shows that the variation in students' 
understanding of physics concepts was due to joint effect of students' scientific imagination and students' scientific concept formation. This implies that much of the variation in students' understanding of physics concepts was due to other factors other than students' scientific imagination and students' scientific concept formation. This finding tends to agreed with the study of Meyer (2010) who found a correlation between students' imagination and mental modeling skills. In order to improve abstraction skills, amplify particular imaginative skill categories was possible through direct and purposeful activity. Meyer, also find out that being meta-cognitive about the use of imagination might improve students' learning outcome. This finding is in consonance with the present study to conform that students' understanding of physics concepts is enhanced as students' scientific imagination facilitates students' scientific concept formation. The implication is that it creates an understanding of the situation that needs problemsolving, but may not be at variance to scientific understanding. Imagination is the ability to think of ways of dealing with difficulties or problems and form images and ideas in the mind. In scientific imagination, students may construct whatever entities they like and attribute them with whatever nature and behaviour they wish, but having done so, definite consequences follow.

There was a direct positive relationship among students' scientific explanation of phenomenon, students' scientific concept formation and students' understanding of physics concepts. The coefficient of determination $\left(\mathrm{R}^{2}\right)$ indicates that, $48 \%$ of variation in students' understanding of physics concepts is attributed to joint effect of students' scientific explanation of phenomenon and students' scientific concept formation on students' understanding of physics concepts. This is an indication that $52 \%$ of the variation in students' understanding of physics concepts is attributed to other factors other than joint effect of students' scientific explanation of phenomenon and students' scientific concept formation. The finding of this study corroborates the finding of Oluwatelure (2002) who found that explanations given by students on scientific phenomenon corresponds to their level of imagination. And Grotzer, (1999) findings agreed that how concepts are formed in student's mind and most importantly how they are connected with each other determines deep understanding. The finding of Oluwatelure, Grotzer and Madu agreed with the current study as to confirm how joint effect of students' scientific explanation of phenomenon and students' scientific concept formation facilitated students' understanding of physics concepts.

There existed a direct positive relationship among students' scientific explanation of phenomenon, students' scientific imagination, students' scientific concept formation and students' understanding of physics concepts. This coefficient of determination $\left(\mathrm{R}^{2}\right)$ indicates that, $49 \%$ of variation in students' understanding of physics concepts is attributed to the joint effect of students' scientific explanation of phenomenon, students' scientific imagination and students' scientific concept formation. This is an indication that $51 \%$ of the variation in students' understanding of physics concepts is attributed to other factors other than joint effect of students' scientific explanation of phenomenon, students' scientific imagination and students' scientific concept formation. The finding of Baser (2006) revealed that students' understanding is improved if cognitive conflict based instruction is fostered. Hence, this finding is in agreement with the current finding that students' understanding of physics concepts improved if students' scientific explanation of phenomenon, imagination and concept formation are facilitated.

\section{Conclusions}

The findings of the study revealed that there was a direct positive relationship among students' scientific explanation of phenomenon, scientific imagination, scientific concept formation and students' understanding of physics concepts. And a statistically significant relationship among students' scientific explanation of phenomenon, students' scientific imagination, students' scientific concept formation and students' understanding of physics concepts. The regression analysis output at .05 level of significance showed the predicted indices of the variation in students' understanding of physics concepts attributed to students' scientific explanation of phenomenon, students' scientific imagination and students' scientific concept formation. However, these variations indicated the relative importance of each variable to the prediction of students' understanding of physics concepts.

\section{Recommendations}

Based on the findings of this study, the following recommendations were made: Physics teachers, the Authors and Publishers of physics textbooks should facilitate students' scientific explanation of phenomenon, students' scientific imagination, students' scientific concept formation so as to improve students' understanding of physics concepts by applying physics concepts learnt into everyday phenomena that students observe and experience. Also, physics teachers should place more emphasis on the most important ideas, principles underlying physics concepts and their relevance to the world.

\section{Reference}

Adeyemo, S.A. (2010). Teaching/learning of physics in Nigerian secondary schools: The curriculum transformation, issues, problems and prospects. International of Journal of Education Research and 
Technology, 1(1) 99-111.

Baser, M. (2006). Fostering conceptual change by cognitive conflict based instruction on students' understanding. Eurasia journal of mathematics, science and technology education, 2 (2) 96 -114.

Chance P. (1994). Learning and Behaviour (Third Edition) California: Brooks/Cole Publishing Comp.

Colman, A. M. (2003). Oxford Dictionary of Psychology Oxford: University Press.

Egan, K. (1992). Imagination in teaching and learning. Chicago: University of Chicago Press.

Ezenwa, V. I., \& Gambari, A. I. (2011). Current innovative instructional methods and technologies for quality tertiary education. Journal of Science, Technology, Mathematics and Education, 80), 302-320. Available online at http://www.iostmed.com

Girard, M., and Wong, D. (2002). An aesthetic (deweyan) perspective on science learning: case studies of three fourth graders. The elementary school journal, 102(3), 199-224.

Griffith, W. T., and Brosing J. W. (2009). The Physics of Everyday Phenomena: A Conceptual Introduction to Physics. 6th edition. McGraw-Hill Companies, Inc., New York.

Grotzer, T. (1999). Cognitive issue that affects math and science learning: Understanding counts: Teaching depth in math and science, project zero. Math/science matter: resource booklets on research in math and science learning: Booklet 1: Harvard Graduate School of Education.

Ivowi, U. M. O. (1983). Achievement level in understanding physics concepts in secondary schools. Journal of Research in Curriculum. 1, 2, 23-24.

Ivowi, U. M. O. (2011). Students' misconceptions about conservation principles and fields. In B .B. Akpan (eds), Perspectives on the education and science teaching. Lagos: foremost educational services LTD.

Jegede, S. A., \& Awodun, A.O. (2013) Impact of Metacognitive Strategies of Textbook Reading on Students' Learning of Physics in Secondary Schools. International Journal of Science and Research (IJSR), 2(6), 470474. Available online at http://wxvw.ijsr.net.

Kaur, R. (2014). Concept Formation Notes for B. Ed Class - IP University. Retrieved from http://raman deep kyahoo.co.uk 4 on 12/01/2014

Khan, A. S. (2011). Existing Level of Understanding of Concepts in the Subject of Chemistry Among Class IX Students and Effects of Teaching Chemistry Through Concept Formation Teaching Model On Students' Achievement. International Islam University, Islamabad.

Kim, E. \& Pak, S. (2001). Students do not overcome conceptual difficulties after solving 1000 traditional problems; American Journal of Physics 70 (7): 759.

Lawson, A. E., \& Verah, M. P. (1993). The Role of Hypothetic deductive Reasoning and Analogous of Molecular interacting in conceptual change. Journal of research in science teaching 30 (9), 1073-1085.

Lawson, R. A. and McDermott, L. C. (1992) "Student understanding of work- energy and impulse-momentum theorems," Am. J Phys. 55, 811-817

Madu, B. C. (2003). Effect of constructivist-based instructional approach on students' conceptual change and retention in physics. Unpublished Ph.D. Theses, University of Nigeria, Nsukka.

Madu, B. C. (2009). Exploring students' conceptions in wave concepts. Trends in Educational Studies Journal 4(1), 18-24.

Michelini, M., Santi, I., Stefanel, A, and Vercellati, S. (2014). Building Vertical Paths in Exploring Magnetic Phenomena Developing Formal Thinking: University of Udine, Physics Education Research Unit, DCFA, Udine, Italy.

$\mathrm{Ng}, \mathrm{W}$. and Nguyen, V. T. (2006). Investigating the Integration of Everyday Phenomena and Practical Work on Physics Teaching in Vietnamese High Schools. International Education Journal, 70, 36-50.

Nnachi, R. O. (2009). Advanced psychology of learning and scientific enquiries. Owerri: Totan publishers.

Nworgu, B. G. (2015). Educational research: Basics issues and methodology (3rd ed.) Nsukka: wisdom Publisher Ltd.

Oluwatelure T. A (2002). Children's Explanation of Scientific Phenomena, Imagination and Concept Formation: Topical Issues in Research and Education. University of Ado Ekiti, 9. 79- 90.

Orji, E. I. (2013). Relative effects of cognitive conflict instructional strategy and conceptual change pedagogy on students' conceptual change and attention in temperature and heat. Unpublished Master in Education (Science Education) thesis, University of Nigeria, Nsukka.

Ostergaard, E., Dahlin B., Hugo, A., (2007). From Phenomenon to concept: Designing Phenomenological science education. 6th IOSTE Symposium for Central and Bastern Europe.

Parker, W. C. (2008). Pluto's demotion and deep conceptual learning in social studies. Social studies review spring ssummer. Teaching history.org

Slotta, J. D, Chi, M. T. H and Joran, E (1995). Assessing Students' Misclassifications of Physics Concepts: An Ontological Basis for Conceptual Change. Learning Research and Development Center: University of Pittsburgh.

Stinner, A. (2003). Scientific method, imagination, and the teaching of physics, Physics in Canada, 59 (6) 335 - 
346

Ugwuanyi, C. S. (2012). Assessment of senior secondary students' conceptual understanding on force and motion. Unpublished Med thesis, University of Nigeria, Nsukka.

Viennot, L. (2003). Teaching Physics. London: Kluwer Publishers.

Westen, D. (1996). Psychology: Mind, Brain and Culture. New York. John Wiley and Sons, Inc.

Wilkinson, J. W. (1999). Teachers' perceptions of the contextual approach to teaching VCE

Yao, Y. Y. (2003). A step towards the foundations of data mining in: Data Mining and Knowledge Discovery: Theory, Tools, and Technology V, Dasarathy, By. (Ed.), The International Society for Optical Engineering, 254-263. 